terminations in 1888 and 1893 , and the Council of the Paris Observatory have recommended that this work should be undertaken in concert with Greenwich Observatory. As a preliminary to the actual longitude operations, it seems essential that the instruments to be used by both parties of observers should be thoroughly tested at contiguous stations.

\section{SPURIOUS EARTHQUAKES.}

I $\mathrm{N}$ compiling the seismic record of any country, we are liable to errors from two sources. We cannot help omitting a large number of slight earthquakes, which it is difficult to separate from the countless tremors that are artificially produced. On the other hand, we include a smaller, but still important, number of shocks which are not seismic in their origin, though they simulate earthquakes in many ways. Errors of the former class are, of course, difficult to prevent, though they tend to become less frequent when attention is given to the subject. Those of the latter class may sometimes be eliminated by a study of the different kinds of disturbance which have been, or might be, mistaken for true earthquakes.

The majority of spurious earthquakes in this country are produced by the firing of heavy guns, the bursting of meteorites, and the fall of rocks in underground channels. Explosions and landslips produce disturbances which are at first frequently mistaken for earthquakes, but their real origin cannot fail to be soon discovered and remembered. Perceptible tremors are also produced in buildings by thunder, but it is improbable that permanent errors can thus arise, for the long duration of the sound, in conjunction with the small area affected, provides a simple test. I shall, therefore, confine myself to the first three causes mentioned in this paper.

\section{Firing of Heavy Guns.}

The sound and tremor produced by the firing of heavy guns are sometimes perceived at great distances; but, as I propose to deal with this subject in another paper, I will merely mention here that observations of the sound at distances exceeding one hundred miles are by no means uncommon.

On two or three occasions within the last few years I have been able to trace supposed earthquakes to this source. On the first (January 7,1890 ), two shocks were felt in the southwest of Essex at 12.30 and 1.25 p.m. All the places from which I received accounts lie close to a line running north-east from Woolwich, with one exception, in which the direction is north by east. I have no report of the direction of the wind in the immediate neighbourhood, but southerly and southwesterly breezes were generally prevalent over the whole country on that day. Near the boundary of the district affected, the disturbance was supposed to be seismic by observers who felt the Essex earthquake of 1884 : somewhat nearer the origin, the sound resembled the report of a heavy gun; while, six miles from. Woolwich, the noise and shock were referred without hesitation to their true cause, the discharge of a Iro-ton gun at Woolwich at the times mentioned. ${ }^{1}$

On May 5-6, I893, a number of shocks were felt at nearly regular intervals in the Isle of Man. At Douglas, where they were very slight, they were regarded as earthquakes; further south, at and near Castletown, they were described as resembling the reports of heavy guns, but the likeness was not striking enough to raise doubts as to their seismic character when it was once asserted; at the Chickens Lighthouse, off the extreme southern point, the keeper informed me that no earthquakes were felt, but that there must have been some man-of war prac tising to the south-south-west; and this, on inquiry at the Admiralty, was found to have been the case, II.M.S. Neptune, a first-class battle-ship, having been engaged in heavy-gun practice to the south of the island during the very times when the reported earthquakes were heard and felt.

Tests. - The principal tests by which the true character of these disturbances may be distinguished are the following: (I) When several are noticed on one day, they are of not very unequal intensity, and may occur at nearly regular intervals. (2) The disturbance is apparently communicated through the air. (3) The gradually increasing confidence in one direction with which the shocks are attributed to gun-firing is no doubt the most important test. (4) In many cases, the position of 1 The supposed earthquake at Chelmsford on January 7 (NATURE, vol. xli., 1890, p. 369 ).

$$
\text { NO. I } 545 \text {, VOL. 6O] }
$$

the disturbed area or the time of occurrence may lead to suspicions regarding the seismic nature of the shocks. (5) If the disturbed area were extensive, a few good time-observations would give a velocity approximating to that of sound-waves in air.

The Bursting of Meteorites.

The explosive bursting of meteorites is one of the commonest causes of spurious earthquakes. The mistake in such cases, it is probable, arises not so much from any close similarity between the two phenomena, as from the exclusion in the minds of the reporters of all artificial causes, and the consequent inference of a seismic origin. The explosion of a large meteor, weighing one or several tons, on entering the atmosphere is heard, according to the late Prof. If. A. Newton, for " a hundred miles around, shaking the air and the houses over the whole region like an earthquake." (NATURE, vol. xxxiv., 1886, p. 533). Many such cases might be quoted, and a very large number must be known to those who have made a special study of the subject, but the following are probably sufficient for the present purpose.

West of England Meteorite, January 25, I894.-At an early stage of its flight, this meteor, according to Mr. Denning, passed over Chester at a height of fifty-eight miles. It travelled in a direction from N.N.W. to S.S.E., passing almost over Droitwich and Worcester, at a height of ahout twentythree miles, and disappearing with an explosion when about sixteen miles above a point four miles north of Ashchurch (near Tewkesbury). Two minutes after its disappearance three detonations were heard at Worcester, "the last being of exceptional violence, shaking buildings and causing the earth to vibrate." At Brinscombe (near Stroud), about a minute or a minute and a half after its disappearance, "there came (apparently from the north-east) a series of explosions, which sounded ... like a number of field-pieces fired in rapid succession, followed by a volley of musketry." One of the most interesting observations from the present point of view is that made by an observer at Parkfields (near Ross). "A slight earthquake," he says, "was felt here. . . . I heard a loud rumbling noise like an explosion, lasting two or three seconds, which I took for thunder. A young lady who had just gone up to her room tells me that there were two slight shocks, the motion being similar to that of a steamer at sea. ... I am informed that it was accompanied by a lurid light, which lasted some time, and that objects at a considerable distance were plainly visible. The night was dark and cloudy, with some rain." The recorded observations are too few in number to determine the boundaries of the sound-area and disturbed area, but a perceptible tremor was felt at Alvechurch (near Redditch), which is thirty-nine miles from Ross, and the sound was heard at Alvechurch and Brinscombe, places which are forty-four miles apart. ${ }^{1}$

Central England Meteorite, November 20, 1887.-At about 8.20 a.m. a loud sound, accompanied in many cases by a distinct trembling or shaking of houses, was heard over a large area, chiefly in the counties of Cambridge, Bedford, Hertford, Buckingham, Oxford and Berkshire. Many observers at once attributed the phenomena to an earthquake, and Mr. H. G. Fordham, who has made a careful study of them, ${ }^{2}$ commenced his inquiries under that impression. It soon appeared, however, that the disturbance proceeded from the air rather than from the ground, and this fact, together with the actual observation of a meteor at the time mentioned, placed its true origin beyond doubt.

The accompanying map is, in part, a reproduction of that prepared by Mr. Fordham; but my object being somewhat different from his, I have added some details and omitted others. Every place where the sound was heard without any mention being made of an accompanying tremor is denoted by a small cross. If the concussion was strong enough to make doors, windows, and other loose objects rattle, the place of observation is shown by a large dot; if the tremor only is mentioned, without any other indication of its intensity, it is marked by a small dot. The sound-area as thus drawn is about J05 miles in length and nearly forty miles in breadth.

From the grouping of the places, where the sound was especially loud and definite, Mr. Fordham believes that the track of the meteorite would probably be best defined by a line drawn from Barrington (near Cambridge) to Wantage. Assuming this line

I Nature, vol. xlix., I894, pp. 324-325; The Times, January 29, 3I, 1894. -The meteorite of November 20, 1887.-Hertfordshire vat. Hist. Soc. Trans., vol. v., 1888, pp. $33^{-62}$. 
to be correct, the observation of the meteor from Hertford would show that it was first seen when at a height of about thirty miles above East Harling, in the south of Norfolk, and that when above a point (indicated on the map by a star) about south-east of Ampthill, an explosion occurred which broke off part of the crust of the meteorite. At two other points (also marked by stars) in the neighbourhoods of Thame and of Abingdon and Wantage, explosions seemed to have uccurred, the latter terminating the course of the meteorite.

Some additional evidence is furnished by the grouping of the places where the sound of the explosion was accompanied by a distinct tremor. The two dotted curves on the map bound all places (with two exceptions) where the concussion was strong enough to rattle doors, windows, crockery, \&c. The form and dimensions of the larger of these curves show that the first explosion must have occupied an appreciable fraction of a second. One or, perhaps, two curves might be drawn surrounding the places from which tremors are recorded, but owing to the small number of such places between the dotted curves, it is uncertain whether it should be a single dumb-bell-shaped curve or two detached curves. It will be seen at a glance that the points which Mr. Fordham indicates for the Ampthill and Abingdon explosions lie very near the centres of the areas bounded by the dotted lines. The explosion above Thame was apparently too slight to produce any concussion on the surface of the ground.

Tests.-(I) The extremely elongated form of the disturbed area, and its great length when the slightness of the vibration is

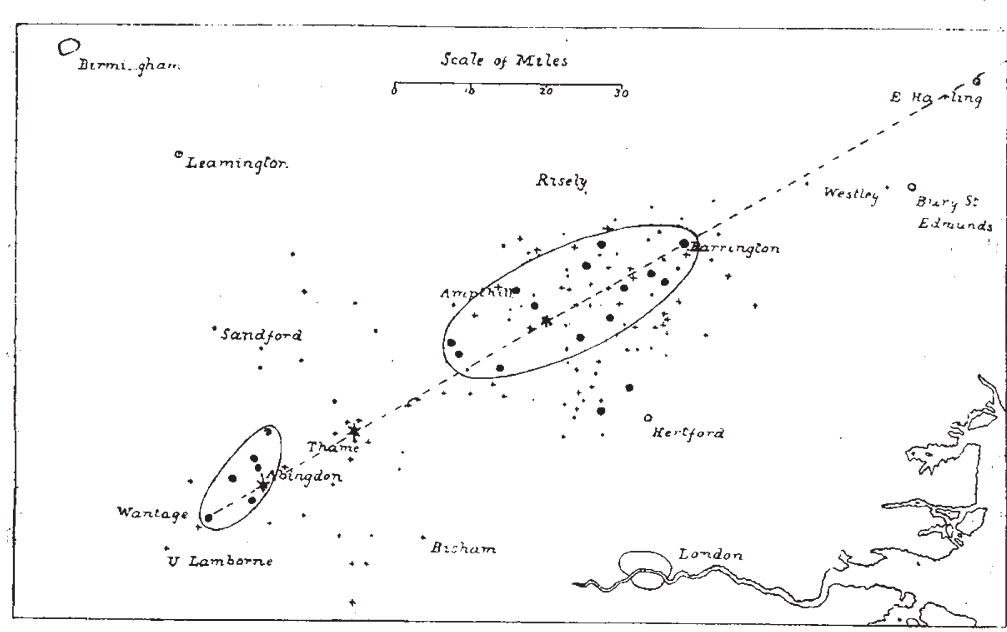

taken into account; the detached isoseismal lines in those cases where there are two or more explosions. (2) The sound is far more prominent than the vibration, which is never the case all over the disturbed area of an earthquake unless that area is a very small one; also, the sound-area overlaps the disturbed area on all sides, and this is only the case with very weak earth quakes. (3) The character of the sound, often consisting of a series of explosions. (4) The obvious transmission of the soundvibrations through the air. Though I have examined many thousands of earthquake-records, the sound is almost uniformly described by the writers as of underground origin. (5) The vibration of doors, windows, \&c., is evidently a concussion due to the impact of air-waves. Occasionally a tremor is actually felt, but, as in the case of a heavy thunder-clap, this is no doubt due to the same cause. (6) The evidence of barograms may be useful in those cases where there is reason to believe that the movement is not due simply to the disturbance of the recording arm. (7) The actual observation of the meteor, or, if the sky be covered, of the glare of its light through the clouds.

\section{Rock-Falis in Underground Channels.}

The fall of rock-masses in underground channels was for long regarded with favour as a possible cause of earthquakes. ${ }^{1}$ No

1 I need not do more than refer to the subsidences in certain well-known districts which are almost entirely undermined by coal-pits or brine chan nels. The disturbance is sometimes described as resembling a severe earthquake, but there could hardly be more than a momentary confusion between the two phenomena.

NO. I 545 , VOL. 6o] great and widely-felt shock would now be attributed to such a cause, but there are certain local earth-shakes which may reasonably be accounted for in this manner. The fall of a heavy mass of rock is evidently capable of producing the observed effects such as are described below. For example, towards the close of last century, one or more of the great upright stones of Stonehenge suddenly fell. According to Mallet, "the shock feit in all the neighbouring hamlets was so great that for some time, until the cause was discovered, it was thought to have been an earthquake, as in fact it was, though not produced by natural causes." 1

Earth-Shakes in the Rhondda Valley.-In the Rhondda Valley in south-east Wales, there are frequent earth-shakes, which seem to be due to rock-falls in the deserted pit-workings by which the region is honeycombed. In many of the published accounts of these disturbances, there is evidently much exaggeration; but there can be no doubt that the shocks are sometimes strong enough to cause windows and doors to rattle loudly, and even to give rise to a distinct rocking sensation. The shocks are accompanied by a noise which is generally compared to the thud produced by the fall of a heavy body, or to the report of a colliery explosion or a distant gun. They also seem to be felt quite as severely in the mines as on the surface, and alarm the men at work, who naturally attribute the phenomena to an explosion. On a recent occasion (October 16, 1896), a miner, who was working in the Gelli pit, informs me that he heard one loud boom, like the discharging of a shot in rock, followed by a slight rumbiing; "but others working in the same pit had a severe shaking, the tools springing off the floor, the dust rising in clouds off the bottom." Again, in the three cases (June 22, 1889; April II, 1894; and October 16,1896$)$ which I have studied, the disturbed areas are roughly circular, and the diameters are small, being, respectively, about one, six and three miles in length; and the second of these is said to have been by far the strongest recently felt in the district. The centres of the three areas are close together, the two extreme ones being five miles apart, and they follow roughly the line of the Rhondda Valley. Now, the rapid diminution in intensity from the centre outwards implies a very shallow focus ; the shock and sound are by nature such as would be produced by the fall of a heavy mass of rock, underground passages exist at no great depth, and subsidences at the surface are known to occur, for houses have been destroyed in this way in many parts of the district. The evidence in favour of the view that the so-called earthquakes are spurious is therefore strong; but the crucial test, that of finding the fallen mass, has, so far as I know, never yet been satisfied.

Earth-Shakes at Sunderland.-A similar, though less artificial, origin may be urged with equal force for the remarkable series of earth-shakes which are occasionally felt in and near Sunderland. These have been described and the theory of their origin clearly worked out in an admirable paper ${ }^{2}$ by Prof. G. A. Lebour, from which the following details are taken. The disturbances consist of sudden shakes, strong enough to make crockery and windows rattle, often, but not always, accompanied by loud noises and dull rumbles. They are, moreover, singularly local, being almost entirely confined to the south-west part of the town, and, apparently, to certain linear bands within that part. As in the case of the Rhondda Valley shocks, the foci must be situated at slight depths, and the phenomena are such as would result from underground rock-falls. It is also certain that the necessary channels exist, for the magnesian limestone, on which Sunderland is built, is simply riddled with cavities of every size and shape, the origin of which is not far to seek. In the midst of the hardest and most compact portions of the limestone, there occur masses of soft pulverulent earthy

1 Roy. Irish Acrd. Trans., vol. xxi., 1848, p. 63

2 "On the Breccia-Gashes of the Durham Coast and some Recent EarthShakes at sunderland." (North of England Inst. of Min. Eng. Trans., vol. xxxiii., 1884, pp. 165-174.) See also Geol. Mag., vol. ii., 1885, pp. 513515 . 
matter, which are readily removed by the mechanica action of percolating rain-water. In such naturally-formed gullets run the feeders of water that are met with in sinking through the magnesian limestone, and these feeders, by chemical action, must cause much additional destruction of the rock. Quite apart from the water which runs off into the sea, that which is pumped up annually by the local water company is estimated to contain lime and magnesia in solution corresponding to nearly forty cubic yards of solid rock.

It seems evident that masses of rock must from time to time fall from the roofs of channels so formed. But we are not here left entirely to conjecture, for, at numerous points along the Durham coast, sections of such channels are exposed that are entirely filled up by angular fragments of the very rock which forms the cliff, and bound together by a cement of the same material. The "breccia-gashes," as they have been termed by Prof. Lebour, vary in width from a few feet to many yards; they are almost invariably narrow at the bottom, and generally wide at the top. "In some cases the broken fragments within the fissures can be traced graduating through semi-brecciated portions of beds to wholly undisturbed strata in the walls or fissure-cheeks. When the top of a fissure is exposed in section, the breccia is also seen usually to pass gradually upwards, first into semi-brecciated matter, and finally to undisturbed or only slightly synclinal beds bridging over the mass of broken rock. When the entire transverse section of a fissure is exposed, it is seen to be a deep V-shaped ravine or gullet, tapering to a point below, and the rocks below it are wholly undisturbed" (p. r66).

Tests.--Individual spurious earthquakes belonging to this class are the most troublesome of all to investigate, for, in most cases, we have to rely on circumstantial evidence alone. The principal tests will be obvious from the above descriptions. They are: (I) the small disturbed area and the comparatively great intensity near its centre; (2) the nature of the shock and sound; (3) the known or inferred honeycombed structure of the district, and the occurrence at other times of subsidences at the surface.

Charles Davison.

\section{REPORT OF THE LONDON TECHNICAL EDUCATION BOARD.}

THE annual report of the Technical Education Board of the London County Council was recently presented to the Council. The following paragraphs of the report, referring to the Board's relations with the Department of Science and Art and with the new London University, are abridged from the Technical Education Gazette.

\section{Relations zvith the Department of Science and Art.}

The Council has been recognised by the Department of Science and Art as the local authority responsible for science and art instruction within the area of the County of London in accordance with Clause VII. of the Science and Art Directory. The powers and duties which such recognition may give have been delegated by the Council to the Board in the same way as the powers conferred by the Technical Instruction Acts were delegated. Ever since the passing of the Technical Instruction Act in 1889 , the Science and Art Department has been in the position of the central authority for technical instruction, and the county councils and county borough councils have been in the position of local authorities for technical instruction. Clause VII. introduced a certain readjustment of duties as between the central authority and the local authorities. No new powers are conferred outside the provisions of the Technical Instruction Acts, but the clause provides for some of the functions under those Acts which have hitherto been discharged by the central authority being delegated to the local authority. Over thirty counties and county boroughs have availed themselves of the clause, and it is stated by those who have had experience of the working of the new system that it is advantageous both to particular schools and to the district generally.

The principal benefits which the Board anticipates from the working of Clause VII, in London are the following :-

(a) Increased facilities for coordinating and organising science and art work in accordance with the particular needs of each locality.

(b) Greater regularity and promptitude in the payment of the grants earned on the Department's examinations.

NO. I 545 , VOL. 60$]$ (c) Increased opportunities for urging upon the Department such modifications in their courses of instruction as may be specially required by the circumstances of London schools and institutions.

The Technical Instruction Act of I 889 affords, perhaps, the first legislative example in educational work of adaptation to special local requirements. In the definition of technical in struction the Act includes " any other form of instruction (in. cluding modern languages and commercial and agricultural subjects), which nay for the time being be sanctioned by that Department [the Department of Science and Art] by a minute laid before Parliament and made on the representation of a local authority that such a form of instruction is required by the circumstances of its district." The Technical Instruction Act having provided for the creation of powerful and disinterested authorities for the conduct and supervision of technical in struction over large areas, Parliament, in the words quoted above, expressed its willingness to give to these authorities an important part in determining the particular field of education which should come within their influence, thus enabling both the matter and the manner of education to be adapted to local needs, It is reasonable to suppose that the same principle will now apply in connection with the subjects of technical instruction which are defined by detailed syllabuses in the Science and Art Directory. The Department has already expressed its willingness to meet the wishes of the local authorities in respect of several administrative details.

The New University of London.

In order to formulate the Board's views with regard to the new University, a special sub-committee was last year established for the purpose of investigating the whole subject and reporting to the Board as to the steps which might be deemed necessary for making representations to the Commissioners on any points in which the Board might be specially interested. In pursuance of this policy, the Board forwarded to the Commissioners an expression of its views upon certain matters. In particular, the Board urged upon the Commissioners the desirability of recognising separate faculties for engineering and for economic and commercial science. The Board's representations were supported by similar expressions of opinion from other quarters, and the Commissioners have come to the decision to adopt the policy which the Board favoured. In the draft statutes which they have prepared for the new University, they have decided to provide for $(a)$ a special faculty of engineering, and $(b)$ a special faculty of economics and political science (including commerce and industry). There is little doubt that the establishment of these faculties will give considerable encouragement to the technical and commercial work in which the Board is specially interested. Recognising the importance of developing the higher departments of these branches of study, the Board has undertaken to allocate to the University out of the funds from time to time placed at its disposal by the Council an annual sum of 2500 ? towards the maintenance of the faculty of engineering in the new University, and a further sum of $2500 l$. towards the maintenance of the faculty of economics and political science (including commerce and industry), on condition that satisfactory arrangements are made in the constitution of the University with regard to evening students, and the recognition and admission to the several faculties of duly qualified teachers in the polytechnics.

\section{UNIVERSITY AND EDUCATIONAL INTELLIGENCE.}

OXFord. - The following is the speech delivered by the Public Orator, Dr. W. W. Merry, on the occasion of his presenting Dr. R. Trimen, F.R.S., for the honorary M.A. degree on May I6:Praesento vobis Ronaldum Trimen, Societatis Regiae Socium, nuper autem Societatis Entornologicae apud Londinium Praesidem. Vir insignis, qui notitiam suam officiosissime impertiendo de Universitate Oxoniensi optime meruit, diu in Africa aus. trali est commoratus, non utique ut gemmas et aurum fodinis erueret neque ut cum Batavis litem sereret, sed ut Naturae arcana altius scrutaretur ac praesertim insectorum inexploratas consuetudines patefaceret.

"In tenui labor, at tenuis non gloria."

Quotus enim quisque mirum illud ingenium quo Natura inermes bestiolas instruxerit vel diligentius investigavit vel exposuit 